Pacific Journal of Mathematic

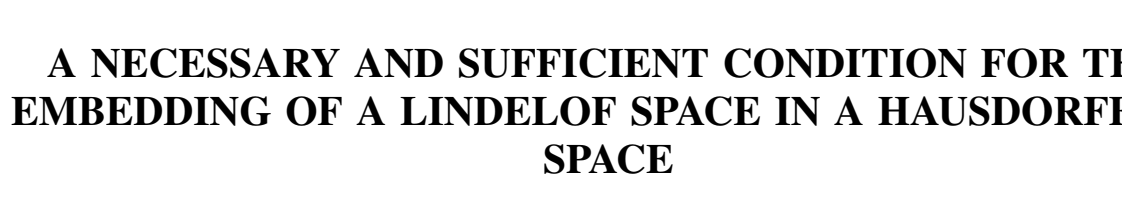




\section{A NECESSARY AND SUFFICIENT CONDITION FOR THE EMBEDDING OF A LINDELOF SPACE IN A HAUSDORFF $\mathscr{\varkappa}_{\sigma}$ SPACE}

\section{BRENDA MACGibBon}

It is known that complete regularity characterizes the Hausdorff topological spaces which are embeddable in a compact Hausdorff space. The theory of $\mathscr{K}$-analytic and $\mathscr{K}$-Borelian sets leads naturally to the search for an analogous criterion for the embedding of a Hausdoff space in a Hausdorff $\mathscr{K}_{\sigma}$ space. (A Hausdorff $\mathscr{K}_{\sigma}$ space is a Hausdorff space which is equal to a countable union of its compact subsets.) We shall give an answer to this problem for Lindelof spaces.

Strong regularity and strong normality of a closed subspace with respect to a given Hausdorff space are defined. It is shown that a Hausdorf Lindelof space is embeddable in a Hausdorff $\mathscr{K}_{o}$ if and only if $X$ is equal to a union of an increasing sequence of its strongly regular closed subspaces. An example is given of a nonregular space which is equal to a union of an increasing sequence of its strongly normal subspaces.

One might think that if a Hausdorff space were equal to a union of an increasing sequence of its closed completely regular subspaces, it would be embeddable in a Hausdorff $\mathscr{K}_{\sigma}$. However, in [3] an example of a Hausdorff space which is equal to a union of an increasing sequence of its closed normal subspaces and which is not embeddable in a Hausdorff $\mathscr{K}_{\sigma}$ is given.

In 1959 in [1], Professor G. Choquet proved that a $\mathscr{K}$-analytic space is embeddable in a space in which it is $\mathscr{K}$-Souslin if and only if it is embeddable in a Hausdorff $\mathscr{K}_{\sigma}$ space. Since all $\mathscr{K}_{\text {-analytic }}$ spaces are Lindelof, it is desirable to characterize Lindelof spaces which are embeddable in Hausdorff $\mathscr{K}_{\sigma}$ spaces.

2. Preliminaries. We will need the following definitions.

DEFINITION 2.1. Let $Y$ be a closed subspace of a Hausdorff topological space $X . \quad Y$ is said to be strongly regular with respect to $X$ if for all subspaces $A$ closed in $Y$ and for all $x \in(Y \backslash A)$, there exist $0, P$ open in $X$ such that:

$$
A \subset 0 ; x \in P ; 0 \cap P=\varnothing \text {. }
$$

Clearly such a subspace $Y$ is a regular topological space in the subspace topology. The converse is false, because there exist closed 
and regular subspaces $Y$ of a Hausdorff space $X$ that are not strongly regular with respect to $X$. For example, let $[0,1]$ have the following topology $\mathscr{T}$ :

$$
0 \in \mathscr{T} \text { if and only if } 0=0^{\prime} \cup\left(0^{\prime \prime} \cap Q\right)
$$

where $0^{\prime}, 0^{\prime \prime}$ are open in the usual topology and $Q$ is the set of rationals in $[0,1]$.

Denote by $X$ the Hausdorff topological space $([0,1], \mathscr{T})$. Let $I$ be the set of irrationals in $[0,1]$; and let $Y=I \cup\{q\}$, where $q$ is a rational in $[0,1]$. Now $Y$ is a closed and regular subspace of $X$, but $Y$ is not strongly regular with respect to $X$ because every open set in $X$ containing $I$ is everywhere dense in $X$.

Definition 2.2. Let $Y$ be a closed subspace of a Hausdorff topological space $X . Y$ is strongly normal with respect to $X$ if for every two closed subspaces $A, B$ of $Y$, there exist open sets $0, P$ in $X$ such that:

$$
A \subset 0 ; B \subset P \text {; and } 0 \cap P=\varnothing \text {. }
$$

Obviously, such a $Y$ is a normal topological space in the subspace topology. But note in the example given above, $Y$ is a closed and normal subspace of $X$, but $Y$ is not strongly normal with respect to $X$.

Now several lemmas concerning these properties will be given.

Lemma 2.1. Let $Y$ be a closed subspace of a Hausdorff space $X$. Then the following conditions are equivalent.

(1) $Y$ is strongly regular with respect to $X$.

(2) For each $y \in Y$ and for each 0 open in $X$ and containing $y$, there exists an open set $P$ in $X$ such that:

$$
y \in P \subset \bar{P}^{x} \subset 0,
$$

where $\bar{P}^{x}=$ the closure of $P$ in $X$.

(3) For each closed $A \subset Y$ and each $y \in(Y \backslash A)$, there exists an open 0 in $X$ such that:

$$
y \in 0 \text { and } \overline{0}^{x} \cap A=\varnothing .
$$

Proof. (The same proof as used to prove regularity in the classical sense.)

LEMMA 2.2. Let $Y$ be a closed subspace of a Hausdorff Lindelof space $X$. If $Y$ is strongly regular with respect to $X, Y$ is strongly normal with respect to $X$. 
Proof. Let $A, B$ be two closed disjoint subspaces of $Y$. After Lemma 2.1 we have:

(1) for each $x \in A$, there exists an open subspace of $X, 0_{x}$ containing $x$, such that:

$$
\overline{0}_{x}^{X} \cap B=\varnothing ;\left(\overline{0}_{x}^{X}=\text { closure of } 0_{x} \text { in } X\right) ;
$$

(2) for each $y \in B$, there exists an open subspace of $X, P_{y}$ containing $y$, such that:

$$
\bar{P}_{y}^{x} \cap A=\mho .
$$

Since $X$ is Lindelof, the open cover of $X$ consisting of

$$
\left\{\left\{0_{x}\right\}_{x} \in A,\left\{P_{y}\right\}_{y} \in B \text { and } X \backslash(A \cup B)\right\}
$$

has a countable subcover. That is, there exist sequences $\left\{0_{n}\right\}_{n=1}^{\infty},\left\{P_{n}\right\}_{n=1}^{\infty}$ of open subsets of $X$ such that:

$A \subset \bigcup_{n=1}^{\infty} 0_{n} ; B \subset \bigcup_{n=1}^{\infty} P_{n} ;$ with $\overline{0}_{n}^{X} \cap B=\bar{P}_{n}^{X} \cap A=\varnothing$ for each $n$. Define $0_{1}^{\prime}=0_{1}$ and $P_{1}^{\prime}=P_{1}$; and by induction for each $n$

$$
0_{n}^{\prime}=0_{n} \backslash \bigcup_{j=1}^{n} \bar{P}_{j}^{X}, P_{n}^{\prime}=P_{n} \mid \bigcup_{j=1}^{n} \overline{0}_{j}^{X} \text {. }
$$

Now $0_{n}^{\prime} \cap P_{j}=\varnothing$ for all $j \leqq n$ implies that $0_{n}^{\prime} \cap P_{j}^{\prime}=\varnothing$ for all $j \leqq n$. Similarly $0_{j} \cap P_{n}^{\prime}=\varnothing$ for all $j \leqq n$ implies that $0_{j}^{\prime} \cap P_{n}^{\prime}=\varnothing$ for all $j \leqq n$. Thus, $0_{j}^{\prime} \cap P_{n}^{\prime}=\varnothing$ for all $j$ and $n$. Then

$$
\left(\bigcup_{j=1}^{\infty} 0_{j}^{\prime}\right) \cap\left(\bigcup_{n=1}^{\infty} P_{n}^{\prime}\right)=\varnothing \text {. }
$$

For each $n, \overline{0}_{n}^{X} \cap B=\bar{P}_{n}^{X} \cap A=\varnothing$. Therefore, $A \subset \bigcup_{j=1}^{\infty} 0_{j}^{\prime}$ and $B \subset \bigcup_{n=1}^{\infty} P_{n}^{\prime}$ and these unions are disjoint. Thus, $Y$ is strongly normal with respect to $X$.

\section{Embedding in Hausdorff $\mathscr{K}_{\sigma}$ spaces.}

THeOREM 3.1. Let $X$ be a Hausdorff Lindelof space. Then a necessary and sufficient condition for $X$ to be embeddable in a Hausdorff $\mathscr{K}_{\sigma}$ space is the following: there exists a sequence $\left\{X_{n}\right\}_{n=1}^{\infty}$ of subspaces of $X$ such that:

(1) $X=\bigcup_{n=1}^{\infty} X_{n}$, and for each $n$

(2) $X_{n} \subset X_{n+1}$

(3) $X_{n}$ is closed and strongly regular with respect to $X$.

Proof. Necessity. By hypothesis, $X$ is embeddable in a Hausdorff $E=\bigcup_{n=1}^{\circ} K_{n}$, where $K_{n}$ is a compact subspace of $E$. Without loss of generality, we can suppose that $K_{n} \subset K_{n+1}$ for each $n$.

Let $X_{n}=K_{n} \cap X$. Obviously, $X=\bigcup_{n=1}^{\infty} X_{n} ; X_{n} \subset X_{n+1}$ for all $n$; 
and $X_{n}$ is a closed and regular subspace of $X$. Moreover, $X_{n}$ is strongly regular with respect to $X$; for suppose that $A$ is closed and contained in $X_{n}$ and $x \in\left(X_{n} \backslash A\right)$. Then $x \notin \bar{A}^{K_{n}}$. Thus, there exist open sets $U, V$ in $E$ such that $x \in U ; \bar{A}^{K} \subset V$; and $U \cap V=\varnothing$. Let $0=U \cap X$ and $P=V \cap X$. Then $x \in 0$ and $A \subset P$ and $0 \cap P=\varnothing$.

Sufficiency. By hypothesis, $X$ is a Hausdorff Lindelof space; $X=\bigcup_{n=1}^{\infty} X_{n}$; and for all $n, X_{n} \subset X_{n+1}$, where $X_{n}$ is closed and strongly regular with respect to $X$.

After Lemma 2.2, $X_{n}$ is strongly normal with respect to $X$. Let $\beta X_{n}$ be the Stone-Cech compactification of $X_{n}$ (for $\left.n=1,2 \cdots\right)$. For all $n, \beta X_{n}$ has a canonical embedding in $\beta X_{n+1}$. Since $X_{n}$ is strongly normal with respect to $X$ for all $n$, then $\beta X_{n}=$ closure of $X_{n}$ in $\beta X_{n+1}$. (This is a consequence of the theorem of Tietze [2].)

For all $n$, let $K_{n}=\beta X_{n}$. Using the canonical embedding of $\beta X_{n}$ in $\beta X_{n+1}$, we can consider $K_{n} \subset K_{n+1}$ for each $n$. Let $E=\bigcup_{n=1}^{\infty} K_{n}$ (or more precisely, the inductive limit of the $K_{n}^{\prime} \mathrm{s}$ ).

To define the required topology on $E$, it is necessary to prove the following lemma.

Lemma 3.2. Let $X=\bigcup_{n=1}^{\infty} X_{n}$ be a Hausdorff Lindelof space, where $X_{n}$ satisfies conditions (1), (2), and (3) of Theorem 3.1 for each n. Let $K_{n}=\beta X_{n}$ for each $n$ (from which it follows that $K_{n} \subset K_{n+1}$ ). For any open subspace 0 of $X$ and for each index $n$, there exists a subset $0_{n}^{*}$ of $K_{n}$ such that:

(i) $0_{n}^{*}$ is an open subspace of $K_{n}$,

(ii) $0_{n}^{*} \cap X_{n}=0 \cap X_{n}$,

and (iii) $0_{n}^{*} \cap K_{n-1}=0_{n-1}^{*}$.

Proof. Let $A=(X \backslash 0)$. Then $A$ is closed in $X$. Let $A_{n}=A \cap X_{n}$ for all $n$. Then $A=\bigcup_{n=1}^{\infty} A_{n}$ and $A_{n+1} \cap X_{n}=A_{n}$ for all $A_{n}$.

Consider $\overline{A_{1} K_{1}}=$ the closure of $A_{1}$ in $K_{1}$. Obviously, $\overline{A_{1}{ }^{K}} \cap X_{1}=A_{1}$ and $\bar{A}_{1}{ }^{K_{1}} \cap\left(X_{2} \backslash X_{1}\right)=\varnothing$ (since $K_{1} \cap\left(X_{2} \backslash X_{1}\right)=\varnothing$ ).

If we consider ${\overline{A_{2}}}_{2}^{K_{2}}$, then ${\overline{A_{1}}}^{K_{1}} \subset{\overline{A_{2}}}^{K_{2}}$ and ${\overline{A_{2}}}^{K_{2}} \cap X_{2}=A_{2}$. It is necessary to show that $\overline{A_{2}{ }^{K_{2}}} \cap K_{1}=\overline{A_{1}}{ }^{K_{1}}$. Obviously, $\overline{A_{1}{ }^{K_{1}}} \subset\left(K_{1} \cap \overline{A_{2}}{ }^{K_{2}}\right)$. Suppose that there exists a $y \in K_{1} \cap\left(K_{1} \backslash \overline{A_{1}{ }^{K_{1}}}\right)=K_{1} \cap\left(K_{2} \backslash \overline{A_{1}}{ }^{K_{1}}\right)$. Then there exists an open neighbourhood $U$ of $y$ in $K_{2}$ such that:

That is

$$
\bar{U}^{K_{2}} \cap{\overline{A_{1}}}^{K_{1}}=\varnothing \text {. }
$$

This implies that $\left(\bar{U}^{K_{2}} \cap A_{2}\right) \cap\left(\bar{U}^{K_{2}} \cap X_{1}\right)=\varnothing$.

Since $X_{2}$ is strongly normal with respect to $X$ and since $K_{2}=\beta X_{2}$, then: 


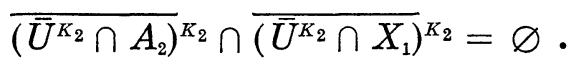

(This is a consequence of the fact that two closed disjoint subspaces in a normal space $Y$ have disjoint closures in $\beta Y$; and this is a consequence of Urysohn's lemma [2].)

Since $y \in K_{1}$, then $y \in{\overline{\left(\bar{U}^{K_{2}} \cap X_{1}\right)}}^{K_{2}}$. Thus $y \notin \overline{\left(\bar{U}^{K_{2}} \cap A_{2}\right)^{K_{2}}}$. Thus, $y \notin \overline{A_{2}}{ }^{K_{2}}$. This shows that $\overline{A_{2}{ }^{K}} \cap K_{1} \subset \overline{A_{1}}{ }^{K_{1}}$; from which it follows that ${\overline{A_{2}}}^{K_{2}} \cap K_{1}=\bar{A}_{1}^{K_{1}}$.

In the same way, it can be shown that for all $n$ :

$$
{\overline{A_{n}}}^{K} \cap K_{n-1}={\overline{A_{n-1}}}^{K_{n-1}} \text {. }
$$

If we let $0_{n}^{*}=K_{n} \backslash \overline{A_{n}}{ }^{K}$; the sequence $\left\{0_{n}^{*}\right\}_{n=1}^{\infty}$ has the required properties.

The end of the proof of Theorem 3.1. For each open set 0 in $X$, let $0^{*}=\bigcup_{n=1}^{\infty} 0_{n}^{*}$, where the $0_{n}^{*}$ were defined above. To show that the $0^{*}$ 's define a base for a topology on $\bigcup_{n=1}^{\infty} K_{n}$, it is necessary to show that $(0 \cap P)^{*}=0^{*} \cap P^{*}$ for any two open subspaces $0, P$ of $X$. Since $0^{*} \cap P^{*}=\bigcup_{n=1}^{\infty}\left(0_{n}^{*} \cap P_{n}^{*}\right)$, it suffices to show for each $n$ that:

$\left(0_{n} \cap P_{n}\right)^{*}=0_{n}^{*} \cap P_{n}^{*}$, where $0_{n}=0 \cap X_{n}$ and $P_{n}=P \cap X_{n}$ for each $n$. Let $A_{n}=X_{n} \backslash 0_{n}$ and $B_{n}=X_{n} \backslash P_{n}$. Then $0_{n}^{*}=K_{n} \backslash \overline{A_{n}}{ }^{K}$ and $P_{n}^{*}=$ $K_{n} \backslash \bar{B}_{n}{ }^{K}$.

Then $\left.0_{n}^{*} \cap P_{n}^{*}=K_{n} \backslash\left(\overline{A_{n}{ }^{K}}{ }^{n} \cup{\overline{B_{n}}}^{K}{ }^{K}\right)=K_{n} \backslash \overline{\left(A_{n} \cup B_{n}\right.}\right)^{K n}$.

Since $A_{n} \cap B_{n}=X_{n} \backslash\left(0_{n} \cup P_{n}\right)$; then, by definition $\left(0_{n} \cap P_{n}\right)^{*}=$

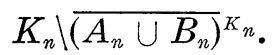

Thus, the $0^{*}$ 's define a base for a topology $\tau$ on $\bigcup_{n=1}^{\infty} K_{n}$. From now on, let $E$ designate the topological space $\left(\bigcup_{n=1}^{\infty} K_{n}, \tau\right)$. By the definition of $\tau, X$ is embedded in $E$.

To show that $E$ is Hausdorff, let $x, y$ be in $E$. Then there exists an $n$ such that $x, y \in K_{n}$. Without loss of generality, let us suppose that $n=1$. Let us choose $U, V$ open in $K_{1}$ such that $x \in U ; y \in V$ and $\bar{U}^{K_{1}} \cap \bar{V}^{K_{1}}=\varnothing$. Let $0_{1}=U \cap X_{1}, P_{1}=V \cap X_{1}$; then $\overline{0}_{1}^{X_{1}} \cap \bar{P}_{1}^{X}=\varnothing$.

From Lemma 2.2, it follows that $X_{1}$ is strongly normal with respect to $X$. Thus, there exist $0, P$ open in $X$ such that $\overline{0}_{1}^{X_{1}} \subset 0^{\prime} ; \bar{P}_{1}^{X_{1}} \subset P^{\prime}$ and $0^{\prime} \cap P^{\prime}=\varnothing$. Thus, there exist $0, P$ open in $X$ such that $0 \cap P=\varnothing$; $0 \cap X_{1}=0_{1}$ and $P \cap X_{1}=P_{1}$.

Let $A=(X \backslash 0) ; B=(X \backslash P)$; and for each $n$ :

$$
\begin{aligned}
& A_{n}=X_{n} \backslash\left(0 \cap X_{n}\right), \\
& B_{n}=X_{n} \backslash\left(P \cap X_{n}\right) .
\end{aligned}
$$

For each $n$, define $0_{n}^{*}=K_{n} \backslash \overline{A_{n} K_{n}} ; P_{n}^{*}=K_{n} \backslash \overline{{B_{n}}^{K}}{ }$. Let $0^{*}=\bigcup_{n=1}^{\infty} 0_{n}^{*}$ 
and $P^{*}=\bigcup_{n=1}^{\infty} P_{n}^{*}$. Since $\left(K_{1} \backslash U\right) \supset \overline{A_{1} K_{1}}$; then $U \subset\left(K_{1} \backslash \overline{A_{1}}{ }^{K_{1}}\right)$; then $0^{*}$ is an open neighborhood of $x$ in $E$. In the same way, it can be shown that $P^{*}$ is a neighborhood of $y$ in $E$. We have already shown that $0^{*} \cap P^{*}=(0 \cap P)^{*}$. Since $0 \cap P=\varnothing$ and $X$ is dense in $E$, then $0^{*} \cap P^{*}=\varnothing$. Thus, $E$ is a Hausdorff space.

Since $E$ is Hausdorff and $0^{*} \cap K_{n}=0_{n}^{*}$ for each $n$; then $K_{n}$ is a compact subspace of $E$. Thus $X$ is embeddable in a Hausdorff $\mathscr{K}_{\sigma}$.

4. An example of a nonregular space satisfying the conditions of the theorem. To show that the theorem is not trivial, we shall give an example of a space satisfying the hypotheses of Theorem 3.1 without being regular.

Let $[0,1]$ have the topology $\mathscr{T}$ already used in the example that follows Definition 2.1. From now on, let $Y$ denote the topological space $([0,1], \mathscr{T}) ; I$ the set of irrationals in $[0,1]$; and $C$ the Cantor set in $[0,1]$.

Consider the following subspace $X$ of $Y$, defined by $X=Z \cup A \cup B$ where:

$$
\begin{aligned}
Z= & C \cap I, \\
A= & Q \cap([0,1] \backslash C), \\
B= & \text { a subset of } I \text { which is countable and dense in }[0,1] \text { with } \\
& \quad \text { respect to the usual topology. }
\end{aligned}
$$

For convenience, let $B=\bigcup_{n=1}^{\infty}\left\{b_{n}\right\}$ and $A=\bigcup_{n=1}^{\infty}\left\{a_{n}\right\}$. (Note that $A$ is not finite.)

Now, let $X=\bigcup_{n=1}^{\infty} X_{n}$, where

$$
X_{n}=Z \cup\left(\bigcup_{j=1}^{n}\left\{b_{j}\right\}\right) \cup\left(\bigcup_{j=1}^{n}\left\{a_{j}\right\}\right) \cdot
$$

It can be shown that $X$ is Lindelof and that $X_{n}$ is strongly normal with respect to $X$. But $X$ is not regular, since $(Z \cup B)$ is closed in $X$ and all open sets that contain $(Z \cup B)$ are everywhere dense in $X$.

I would like to acknowledge my thanks to Professor G. Choquet for reading the manuscript and for his helpful suggestions. 


\section{BIBLIOGRAPHY}

1. G. Choquet, Ensemble $\mathscr{K}$-analytiques et $\mathscr{K}$-Sousliniens. Cas général et cas métrique, Ann. Inst. Fourier 9 (1959), 74-86.

2. J. L. Kelley, General Topology, New York, 1955.

3. B. MacGibbon, Exemple d'espace $\mathscr{K}$-analytique qui n'est $\mathscr{K}$-Souslinien dans aucun espace, Bull. des Sci. Math. 94 (1970), 3-4.

Received January 14, 1970.

MCGill UNIVERSITY

Montreal, Canada 



\section{PACIFIC JOURNAL OF MATHEMATICS}

\section{EDITORS}

\author{
H. SAMELSON \\ Stanford University \\ Stanford, California 94305

\section{Richard Pierce} \\ University of Washington \\ Seattle, Washington 98105
}

J. DugundJI

Department of Mathematics

University of Southern California

Los Angeles, California 90007

RichaRd ARENS

University of California

Los Angeles, California 90024

\section{ASSOCIATE EDITORS}
E. F. BECKENBACH
B. H. NeUMANN
F. WOLE
K. YoshidA

\section{SUPPORTING INSTITUTIONS}

\author{
UNIVERSITY OF BRITISH COLUMBIA \\ CALIFORNIA INSTITUTE OF TECHNOLOGY \\ UNIVERSITY OF CALIFORNIA \\ MONTANA STATE UNIVERSITY \\ UNIVERSITY OF NEVADA \\ NEW MEXICO STATE UNIVERSITY \\ OREGON STATE UNIVERSITY \\ UNIVERSITY OF OREGON \\ OSAKA UNIVERSITY \\ UNIVERSITY OF SOUTHERN CALIFORNIA
}

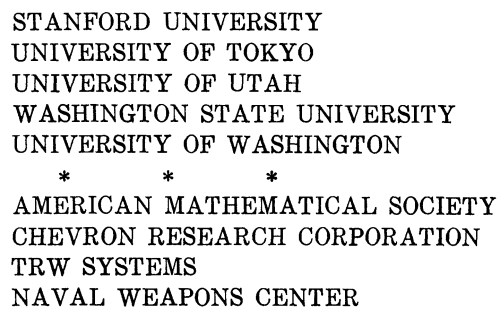

The Supporting Institutions listed above contribute to the cost of publication of this Journal, but they are not owners or publishers and have no responsibility for its content or policies.

Mathematical papers intended for publication in the Pacific Journal of Mathematics should be in typed form or offset-reproduced, (not dittoed), double spaced with large margins. Underline Greek letters in red, German in green, and script in blue. The first paragraph or two must be capable of being used separately as a synopsis of the entire paper. The editorial "we" must not be used in the synopsis, and items of the bibliography should not be cited there unless absolutely necessary, in which case they must be identified by author and Journal, rather than by item number. Manuscripts, in duplicate if possible, may be sent to any one of the four editors. Please classify according to the scheme of Math. Rev. Index to Vol. 39. All other communications to the editors should be addressed to the managing editor, Richard Arens, University of California, Los Angeles, California, 90024.

50 reprints are provided free for each article; additional copies may be obtained at cost in multiples of 50 .

The Pacific Journal of Mathematics is published monthly. Effective with Volume 16 the price per volume (3 numbers) is $\$ 8.00$; single issues, $\$ 3.00$. Special price for current issues to individual faculty members of supporting institutions and to individual members of the American Mathematical Society: $\$ 4.00$ per volume; single issues $\$ 1.50$. Back numbers are available.

Subscriptions, orders for back numbers, and changes of address should be sent to Pacific Journal of Mathematics, 103 Highland Boulevard, Berkeley, California, 94708.

PUBLISHED BY PACIFIC JOURNAL OF MATHEMATICS, A NON-PROFIT CORPORATION

Printed at Kokusai Bunken Insatsusha (International Academic Printing Co., Ltd.), 7-17, Fuj̣imi 2-chome, Chiyoda-ku, Tokyo, Japan. 


\section{Pacific Journal of Mathematics}

\section{Vol. 35, No. $2 \quad$ October, 1970}

Valentin Danilovich Belousov and Palaniappan L. Kannappan, Generalized Bol functional equation .................................... 259

Charles Morgan Biles, Gelfand and Wallman-type compactifications ........... 267

Louis Harvey Blake, A generalization of martingales and two consequent convergence theorems .................................... 279

Dennis K. Burke, On p-spaces and $w \Delta$-spaces..................... 285

John Ben Butler, Jr., Almost smooth perturbations of self-adjoint operators . . . . . . 297

Michael James Cambern, Isomorphisms of $C_{0}(Y)$ onto $C(X) \ldots \ldots \ldots \ldots \ldots . \ldots 307$

David Edwin Cook, A conditionally compact point set with noncompact closure ... 313

Timothy Edwin Cramer, Countable Boolean algebras as subalgebras and homomorphs .........................................

John R. Edwards and Stanley G. Wayment, A v-integral representation for linear operators on spaces of continuous functions with values in topological vector spaces.............................................

Mary Rodriguez Embry, Similarities involving normal operators on Hilbert

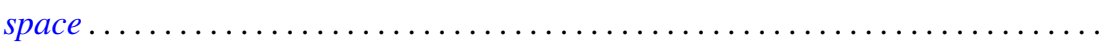

Lynn Harry Erbe, Oscillation theorems for second order linear differential

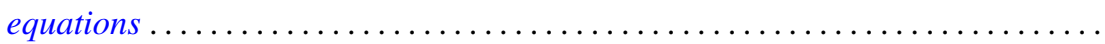

William James Firey, Local behaviour of area functions of convex bodies .......... Joe Wayne Fisher, The primary decomposition theory for modules ..............

Gerald Seymour Garfinkel, Generic splitting algebras for Pic ..................

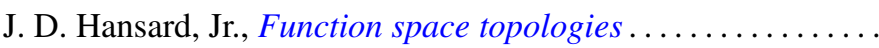

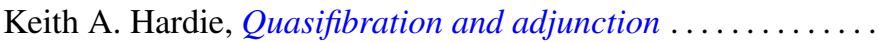

G. Hochschild, Coverings of pro-affine algebraic groups ...........

Gerald L. Itzkowitz, On nets of contractive maps in uniform spaces ..

381

389

399

417

Melven Robert Krom and Myren Laurance Krom, Groups with free nonabelian subgroups....................................

James Robert Kuttler, Upper and lower bounds for eigenvalues by finite differences ......................................

Dany Leviatan, A new approach to representation theory for convolution transforms . . .

Richard Beech Mansfield, Perfect subsets of definable sets of real numbers ...

Brenda MacGibbon, A necessary and sufficient condition for the embedding of a

Lindelof space in a Hausdorff $\mathscr{H} \sigma$ space ..................

David G. Mead and B. D. McLemore, Ritt's question on the Wronskian ....

Edward Yoshio Mikami, Focal points in a control problem .....

Paul G. Miller, Characterizing the distributions of three independent n-dimensional random variables, $X_{1}, X_{2}, X_{3}$, having analytic characteristic functions by the joint distribution of $\left(X_{1}+X_{3}, X_{2}+X_{3}\right)$. . .

P. Rosenthal, On the Bergman integral operator for an elliptic partial differential equation with a singular coefficient....

Douglas B. Smith, On the number of finitely generated $O$-group 